\title{
INDUSTRIALIZAÇÃO EM FEIRA DE SANTANA-BA (2002-2010): PLANEJAMENTO TERRITORIAL E NEODESENVOLVIMENTISMO.
}

\author{
Hidelbergue Machado Santos ${ }^{1}$; \\ Janio Santos ${ }^{2}$ \\ 1. Bolsista de Iniciação Científica do CNPq, Graduado em Geografia, Universidade Estadual de Feira de Santana, e- \\ mail: gutomaxado@hotmail.com \\ 2. Orientador, Doutor em Geografia, Professor Titular, Departamento de Ciências Humanas e Filosofia, Universidade \\ Estadual de Feira de Santana, e-mail: janiosantos@yahoo.com.br
}

Palavras-chave: Industrialização; Centro-Periferia; Planejamento Territorial.

\section{INTRODUÇÃO}

Desde o advento da Revolução Industrial na Europa, a industrialização tornou-se um modelo desejado por diversos países. A indústria, como agente de progresso e superação do atraso, disseminou-se globalmente como uma verdade quase que inquestionável. O processo de industrialização foi moldando-se de acordo com o mercado, passando por diversas formas de organização do trabalho e da produção, o fordismo, taylorismo, acumulação flexível etc., sempre encontrando no sistema capital um meio de manter-se como significante setor produtor de riquezas.

No Brasil, isso não aconteceu de maneira tão diferente, salvo a periodicidade, pois o cenário industrial brasileiro da modernização se deu tardiamente, isso em relação a alguns países centrais, tido como desenvolvidos, tais como Inglaterra e Alemanha, processo de modernização que Becker e Egler (1998) consideram como conservadora.

Dessa forma, este artigo tem como cerne investigar quais foram as mudanças que ocorreram no processo de industrialização em Feira de Santana, no contexto do planejamento territorial entre 2002 a 2010. Portanto, tem como referências as políticas implementadas pelo governo do Partido dos Trabalhadores (PT), na busca por evidenciar as contradições pautadas no projeto geopolítico do Estado, em relação ao planejamento regional, materializado em Feira de Santana-Ba, concebidas por Alves (2014) como um neodesenvolvimentismo.

\section{MATERIAL E MÉTODOS}

A metodologia aplicada teve seus trabalhos sob a perspectiva quali/quantitativa, com análises de segmento que partem do geral para o particular e análises lineares; se utilizou de pesquisa exploratória e documental; pesquisa bibliográfica; observações sistemáticas; e estudo de caso. Foram feitas pesquisas exploratória e documental, pesquisa bibliográfica, por meio de livros, periódicos e produções acadêmicas (teses, dissertações e monografias) para contextualização histórica do fenômeno industrialização no âmbito nacional, estadual e local. Foram feitas visitas de campo no CIS para registrar as indústrias que estão em funcionamento ou inativas. Ainda nessas visitas, foram feitas observações sistemáticas, com o intuito de melhor apreensão da realidade e posterior espacialização, por meio de mapas temáticos, tabelas e gráficos.

Investigou-se a situação da atividade industrial em Feira de Santana nos últimos 15 anos, buscando entender tal realidade. Isso, sem perder de vista a análise do Plano Diretor do CIS e das políticas dos PPAs, que se efetivaram em Feira de Santana, para posteriormente inferir as finalidades e intenções do Estado com essas políticas territoriais.

\section{ANALISE E DISCUSSÃO DOS RESULTADOS}

Realidade apreendida com a pesquisa expressa mudanças que indicam as contradições do planejamento territorial, no projeto geopolítico do Estado, e a realidade empírica da atividade industrial em Feira de Santana, a partir de 2002, pautando-se na dialética marxista, centrada na relação 
entre as classes. Dessas premissas serão analisadas as novas diretrizes do planejamento territorial, voltadas para o setor industrial e que foram e serão implementadas pelo Estado em Feira de Santana.

Sobre o período estudado notou-se que Feira de Santana tem sua dinâmica econômica amplamente concentrada no setor de serviços segundo publicações 2007 - Boletim do PIB Municipal- em 2006 os serviços compreendiam a valores em torno de 2.464 milhões o que correspondia a 4,86\% na participação total do estado. Tal dado confrontado com a realidade do setor industrial expressa a desproporção pois, a indústria em 2008 detinha um expressão em valores de 889 milhões, dados colhidos em publicações da FIEB, (2011) sobre a interiorização da indústria, conforme Tabela 1

Tabela 1 : INDICADORES ECONÔMICOS SELECIONADOS DO MUNICÍPIO DE FEIRA DE SANTANA

\begin{tabular}{|c|c|c|c|c|c|c|c|}
\hline Municipio & População(1) & $\begin{array}{l}\text { PIB (em } \\
\text { R\$ milhōes) }\end{array}$ & $\begin{array}{l}\text { Ranking em } \\
\text { relação ao PIB } \\
\text { (2) }\end{array}$ & $\begin{array}{l}\text { PIB per capita } \\
\text { (em RS) }^{(2)}\end{array}$ & $\begin{array}{l}\text { Valor Adicionado } \\
\text { Indústria } \\
\text { (em RS milhōes) }^{(2)}\end{array}$ & $\begin{array}{l}\text { Número de } \\
\text { Empresas } \\
\text { industriais }^{(3)} \\
\end{array}$ & $\begin{array}{l}\text { Número de } \\
\text { Empregos } \\
\text { industriais }^{(3)} \\
\end{array}$ \\
\hline Feira de Santana & 556.756 & 5.263 & 4 & 9.005 & 889 & 631 & 24.679 \\
\hline Total da Bahia & 14.021 .432 & 121.508 & - & 7.787 & 29.530 & 5.403 & 323.625 \\
\hline Feira/Bahia (\%) & 4,0 & 4,3 & - & 115,6 & 3,0 & 11,7 & 7,6 \\
\hline
\end{tabular}

Dessas publicações, nota-se que com um PIB da ordem de $\mathrm{R} \$ 5,3$ bilhões ( $4^{\mathrm{a}}$ posição no ranking da Bahia). O PIB per capita alcança $\mathrm{R} \$ 9$ mil, sendo 15,6\% superior à média do Estado da Bahia. Frente ao setor de serviços que é responsável por $78,7 \%$ do total da economia, o que demonstra a forte vocação do município, respondendo a indústria por $20,4 \%$ e a agropecuária praticamente inexiste $(0,9 \%)$.

Com relação às empresas industriais em 2010 cadastradas pela FIEB eram de 631 com o emprego de 24.679 trabalhadores. O que caracteriza Feira de Santana como um município diverso em variedade de indústrias com 27 segmentos industriais, entre os quais se destacam: Construção Civil; Fabricação de Produtos de Borracha e de Material Plástico; Produtos Eletrônicos e Ópticos; Fabricação de Produtos Alimentícios e Fabricação de Artigos do Vestuário e Acessórios. Com relação ao crescimento industrial, pode-se analisar o mesmo no Gráfico 1:

Gráfico 1

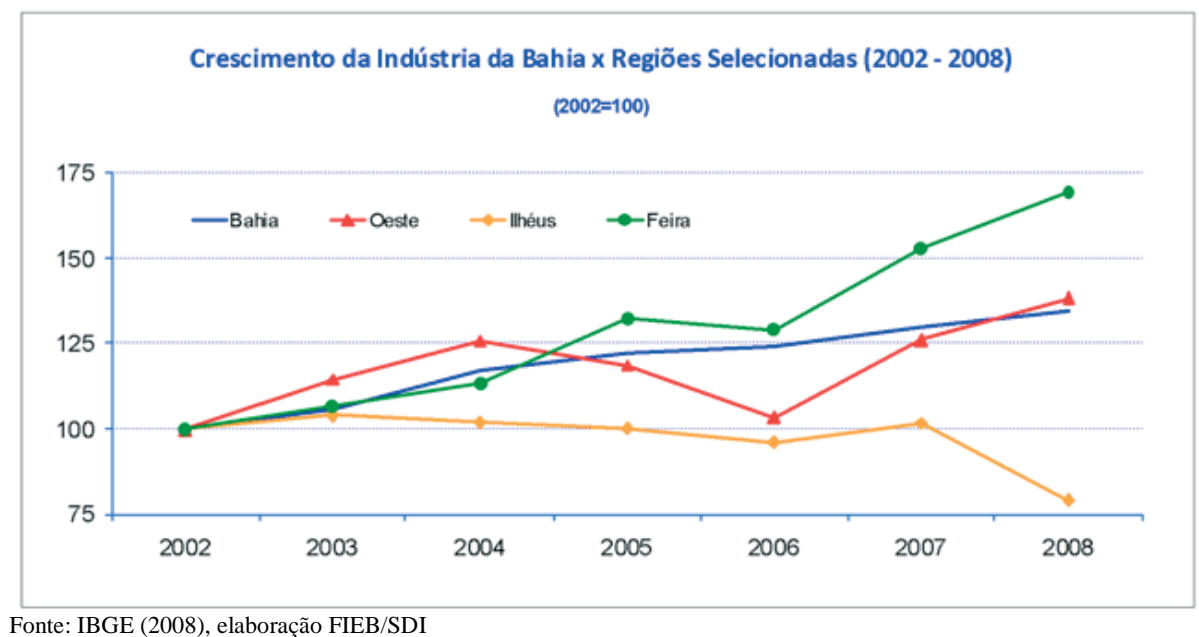

Apreende-se um crescimento constante entre os anos de 2002 a 2008, havendo um aumento considerável a partir de 2006 e que parecem fornecer para o entendimento de que no município as políticas desenvolvidas por o governo do Partido dos Trabalhadores tiveram 
resultados positivos na indústria local, entretanto estas ações precisam ainda de maior investigação, mas o crescimento é regular e positivo, incentivado por certo, devido a sua localização estratégica e pelo modelo das políticas de incentivos dos governos estadual e federal, especialmente as da Sudene.

Percebeu-se também que esse crescimento começa a ter limitações nos anos posteriores ao período de governo de Luíz Inácio, dado que precisa ser melhor investigado, pois sabe-se que em níveis mundiais a crise iniciada nos Estados Unidos no mercado imobiliário repercutira globalmente nas finanças nacionais.

Segundo a FIEB (2015), Feira de Santana em número de empregados na Indústria de Transformação em 2013 decresce para 21.252 e em 2014 para 19.970 incluindo a Indústria de Transformação e Extrativa Mineral.

\section{CONSIDERAÇÕES FINAIS}

Um olhar analítico da realidade sob o governo do PT e suas contradições emergentes do planejamento territorial, adotado em Feira de Santana, permite novas concepções sobre a situação atual do CIS, bem como sobre suas diretrizes. Assim, estudar esse processo de industrialização, por meio do viés sócioespacial, permite uma nova perspectiva sobre a temática, tendo como base o contexto do governo do PT, e pode estabelecer novas estratégias para atuações, tanto na esfera do Estado, como da sociedade civil.

Acredita-se que o crescimento industrial em Feira de Santana adensa o crescimento econômico, porém o mesmo não diminui as desigualdades, preservando as bases capitalistas e contrariando até mesmo a proposta de neodesenvolvimentismo, ao que parece a mesma foi abortada ainda um pouco antes da crise de 2008, pois medidas estratégicas para manter o tripé macroeconômico neoliberal voltaram a oprimir a classe trabalhadora e que disseminou-se afetando não só a industria, mas os diversos setores.

Assim um novo olhar sobre o planejamento tem sido esboçado na pesquisa do autor e um diagnóstico tendo como fito a investigação do CIS mediante políticas de planejamento territorial no governo do PT serão objetivadas em trabalhos posteriores. Se, por um lado, o trabalho ora em evidência não pretende esgotar a discussão do objeto, por outro coloca-se como contribuição para a temática, Feira de Santana, a industrialização e o planejamento territorial.

\section{REFERÊNCIAS}

ALVES, Giovanni. Trabalho e neodesenvolvimentismo: choque de capitalismo e nova degradação do trabalho no Brasil. Bauru: Canal 6, 2014.

BAHIA. FIEB Superintendência de Desenvolvimento Industrial: Gerência de Estudos Técnicos. Outubro de 2015.

FIEB Interiorização da Indústria: Sistema FIEB, 2011.

.SEI Boletim PIB municipal, 2007. Disponível em <WWW.sei.ba.gov.br > acesso em 04052015.

BECKER, Bertha K.; EGLER, Claúdio A. G. Brasil: Uma nova potência regional na economia-mundo. $3^{\text {a }}$ ed. Rio de Janeiro: Bertrand Brasil, 1998. (Coleção Geografia)

CARLOS, A. F. A (re)produção do espaço urbano. São Paulo: EDUSP, 1994.

. Espaço e Indústria. $3^{\text {a }}$ ed. São Paulo: Contexto, 1990 
CASTELLS, M. Sociologia Del Espacio Industrial. Editorial: Syuso. Madrid, 1987.

CRUZ, R. C. da. A inserção de Feira de Santana (BA) nos processos de integração produtiva e desconcentração econômica nacional. 1999. 342f Tese (Doutorado em Economia)- Instituto de Economia, Universidade de Capinas, Campinas, 1999.

FREITAS, Nacelice Barbosa. Urbanização em Feira de Santana: influência da industrialização 1970-1996. 1998. Dissertação (Mestrado em Arquitetura e Urbanismo) Faculdade de Arquitetura, Universidade Federal da Bahia, Salvador, 1998.

GRAMSCI, Antonio. Os Intelectuais e a Organização da Cultura. Rio de Janeiro: Civilização Brasileira, 1979

Brasileira, 1991.

Maquiavel, a política e o estado moderno. 8.ed. Rio de Janeiro: Civilização . Passado e presente. Buenos Aires: Granica, 1974.

HARVEY, David. A condição pós-moderna. 18. ed. São Paulo: Loyola, 2009.

IANNI, Octavio (Org.). Marx: sociologia. SP: Ática, 1992. (Grandes cientistas sociais, 10).

INSTITUTO BRASILEIRO DE GEOGRAFIA E ESTATÍSTICA (IBGE). Censo

Demográfico, 2010. Disponível em: <http://www.ibge.gov.br/censo2010/> . Acesso: 05 Out. 2015.

MARX, Karl. O Capital: crítica da economia política. 18ª ed. São Paulo: Civilização Brasileira, 2001.

MARX, Karl. O 18 Brumário e cartas a Kugelmann. 6. ed. Rio de Janeiro: Paz e Terra, 1997.

OLIVEIRA, Francisco de. Elegia Para uma Re(li)gião. Sudene, Nordeste. Planejamento e conflitos de classe. 5. ed. Rio de Janeiro: Paz e Terra, 1987.

POPPINO, Rollie E. Feira de Santana. Salvador: Itapuã, 1968.

SANTOS, Milton. Do espaço sem nação ao espaço transnacionalizado. In: RATTNER, H. Brasil 1990: caminhos alternativos do desenvolvimento. São Paulo, Editora Brasiliense, 1979, p.143-161.

SCARLATO, Francisco Capuano. População e urbanização brasileira. In: ROSS, Jurandyr L. Sanches (Org.). Geografia do Brasil. 4. ed. São Paulo: Edusp, 2003.

SILVA, Alex de Souza. A influência do Centro Industrial do Subaé (CIS) no processo de urbanização do bairro do Tomba: um estudo de caso no município de Feira de Santana-Ba. Dissertação (Mestrado) UNIFACS. Salvador, 2010. 